\title{
SÍNTESE CRIMINIÁTRICA
}

\author{
H. VEIGA DE CARVALHO
}

\begin{abstract}
Resumo da Conferência pronunciada na 2.a Semana Paulistá de Estudos Policiais, realizada no Instituto de Criminologia do Estado de Sāo Paulo, no dia 24 de setembro de 1940.
\end{abstract}

O estudo do homem delinquente, que já vem de há dezenas de anos, tem empolgado os pesquisadores de todo o mundo; iniciado na luzente terra do Lácio, de lá se difundiu por tôdă a Europa e, dela, para o Mundo, atingindo até os mais recônditos centros de trabalho da Ásia e da América. Aquí, nestas benditas plagas brasileiras, não tem sido pequena a soma de trabalho realizado, desde as memoráveis lições de Nina Rodrigues, o nosso protocriminalista, até as modernas escolas antropocriminológicas, já espalhadas por tôda a Federação Nacional. Grande tem sido a messe recolhida por tão numerosos ceifeiros; é indiscutível o avanço que no campo do conhecimento individual dos criminosos tem sido levado a efeito; sem embargo, e eis o que constitue uma dolorosa verificação, ainda fazemos apenas criminografia. Disse-o quem o poderia afirmar com autoridade: Mestre Afrânio Peixoto - antes que criminologia, fazemos, por enquanto, criminografia; apenas isso: registro dos caracteres de cada um dos criminosos. Escapar-nos-á, ainda, uma idéià geral, de síntese dos conhecimentos enceleirados, que permita alcançar conceitos filosóficos e, por meio deles, assentar as bases duma verdadeira ciência a criminologia.

De facto, não nos será possível restringir minimamente, tão verazes conceitos. Eles estão escudados pela inconteste verificação de todo estudioso dêstes assuntos. E basta-nos uma prova, para nos certifiéarmos disso: bem sabido é que o ápice dos nossos conhecimentos a respeito de qualquer matéria reflete-se pelo arranjo duma classificação e sua competente nomenclatura. Ora, é justamente uma classificação o que ainda não foi possível estabelecer em matéria de estudo dos criminosos, quando menos, até agora. De feito, para classificar, mister se faz conhecer cada uma das individualidades em seus pormenores, para depois conhecer-lhes, os caracteres afins, reconhecendo grupos e distribuindo-os harmonicamente. Sem se ter acabado o estudo criminográfico de todos os tipos de delinquentes; como, então, estabelecer-se uma sua classificação, de que ainda não podemos individualizar os tipos? E' êste o estado actual da questão, 
e tôdás as tentativas de classificar teem esbarrado com tais dificuldades e não teem conseguido o aplauso unânime dos competentes; nem unânimé, nem ao menos de grande número dentre êles. Só em 1885, no Congresso Internacional reunido em Roma foi vencedora a classificação de Ferri mas, assim mesmo, não por muito tempo; e eis que o tema tem voltado repetidamente ao debate dos grandes conclaves científicos e ainda agora vai ser discutido no $20^{\circ}$ Congresso Latino-Americano de Criminologia, sob o aspectô particular da classificação dos penitenciários.

Sem embargo de tudo isso, creio firmemente não ser de pura e indiferente espectativa a atitude a adoptar pelos diversos estudiosos. $\mathrm{E}^{\prime}$ indiscutível, já o disse, o apoucamento dos nossos conhecimentos criminológicos. No entretanto, em matéria de gênese dos 'actos criminosos, está bem e firmemente assente que só dois factores entram em jôgo na determinação dêsses actos: o factor mésológico e o factor biológico. O primeiro será constituido pelo conjunto dos estímulos provenientes do meio exterior, cósmico inclusive, e que também poderia ser chamado factor exógeno ou extrínseco, e o segundo apanhará o conjunto de influências que, oriundas do meio interno, da própria constituição individual do delinquente, contribuem para que êle entre em acção antissocial, e que também poderia ser denominado factor endógeno ou intrínseco. Dentro dêsses dois factores cabem tôdas as modalidades de agentes criminógenos. Assim sendo, e como só se apuram, ao fim, justamente, as influências dêsse binômio tão constante, aí teremos, então, as bases para uma classificação de criminosos, sôbre a qual já tenho várias vezes insistido e que compreenderia os seguintes grupos: 1. Criminosos de gênese puramente biológica: biocriminosos; 2. Criminosos de gênese preponderantemente biológica: biocriminosos preponderàntes; 3. Criminosos de gênese endógeno-exógena, sem se poder estabelecer critério de predomínio: mesobiocriminosos; 4. Criminosos de gênese preponderantemente mesológica: mesocriminosos preponderantes e 5. Criminosos de gênese puramente mesológica: mesocriminosos. Haveria, dest'arte, dois tipos de criminosos puros quanto à sua gênese, só biológica ou só mesológica, e três tipos de associação, tipos mixtos, em que haveria predominância dum ou doutro dos dois factores ou, então, equivalência, pelo menos aparente, entre êles. Seria esta uma classificação verdadeiramente etiológica dos criminosos que, 'quando não estabeleça numerosos grupos, por essa mesma razão, não deixa margem a crítica desfavorável, permitindo sempre encontrar aquele grupo a que pertença o indivíduo devidamente estudado.

Para se aferir a quantidade em que cada um dêsses factores entrou na determinação do acto criminoso é que há complexidade maior a vencer. Esta complexidade refere-se à necessidade dum exame minucioso $\mathrm{e}$ completo do indivíduo delinquente, para determinar-lhe o perfil individual e, também, um exame outro tanto minucioso e completo do meio ambiente e do comportamento social, para precisar qual o modo e o pêso das influências mesológicas. Aqui, há que 
pôr em execução uma análise rigorosa quanto a método e a técnica, impessoal em referência ao analista e cujos moldes deverão sẻr decalcados dos que a medicina emprega em suas indagações. Seria uma verdadeira clínica criminal, belo anseio da criminologia moderna e pela qual já de há muito se vem clamando; em 1936, no $5 .^{\circ}$ Curso de Moléstias Nervosas e Mentais da Policlínica de São Paulo, não me esquecí eu, na oportunidade que se me ofereceu, de lançar também o meu apêlo, que tểnho repetido com insistência e de que espero não me cançar. Esta clínica criminal, 'especializada quanto aos fins que tem em mira, corresponde assáz bem ao qủe o mestre platino Francisco de V.eyga chama com muita felicidade de expressão criminiatria e que é o substracto do que o insigne Director do Manicômio Judiciário do Rio de Janeiro, Prof. Heitor Carrilho, denomina medicini$z a_{c} \tilde{a} o$ do Direito Penal.

Convém, desde já, assinalar que esta intromissão da medicina no campo do direito não visa desalojá-lo e nem substituí-lo. Nada disso. $\mathrm{O}$ que se faz necessário, inadiavelmente indispensável, é que a colaboração da medicina para o direito seja oferecida e aceite pois que dos seus métodos e da sua técnica analítica está a necessitar o elaborador é o aplicador da lei penal (lei penal, na expressão usual mas que também está a reclamar renovamento: lei de defesa social, ou cousa que o valha). Esta colaboração da mediciña para o direito seria qualquer cousa como o que já hoje se admite, por exemplo, no que diz com o cálculo da responsabilidadè à medicina compete verificar qual o gráu da capacidade de receber a imputação de actos- criminosos que compete a um determinado indivíduo, o que é, então, lèvado para a esfera do direito e ao juiz competirá, com base nesise cálculo feito medicamente, acertar qual a responsabilidade legal que caberá ao respectivo indivíduo considerado. À criminiatria viria a competir, justamente, estudar minudentemente o indivíduo e o meio no qual evolucionou e agiu antissocialmente, procurando estabelecer a síntese da sua personalidade, e, em seguida, oferecer aos juristas o resultado de tais indagações para què êstes, assim estribados, viessem a poder alcançar a prolação exacta do tratamento social a adoptar no caso estudado. Como ápice das indagações criminiátricas, estaria o cálculo da influência dos factores criminógenos antes relembrados e, com êsse cálculo estabelecido, a determinação da classe de delinquente a que pertença o indivíduo considerado. Vê-se, assim, que' a medicina tem a oferecer ao direito o seu rigor científico "que, aliado ao rigor científico dos acêrtos jurídicos, viria a constituir uma frente de segurança indestrutível.

Para poderem se desenvolver convenientemente e alcançar a meta que thes compete, as actividades criminiátricas teriam: 1.9 - como método de estudo, a biotipologia criminal; $20^{\circ}-$ como fim, a classificação dos criminosos (que seria o diagnóstico final) e a previsão da sua perigosidade e emendabilidade (que seria o seu prognóstico). Ao direito competiria o tratamento social que, a nós médicos, (pedindo vênia para passarmos além da chinela) parece atingir o máximo 
de perfeição com a pena indețerminada: tratamento de acôrdo com o indivíduo e com a evolução que êle venha a oferecer.

Parece não haver dúvidas quanto ao valor e ao papel que compete desenrolar à clínica criminal, à criminiatria. Se se tentar estabelecer uma síntese criminiátrica, veremos a complexidade de problemas que há a enfrentar para se poder alcançá-la. Mas não se poderia contar, mesmo, com um caminho desembaraçado, bastando lembrarmo-nos que estamos a tratar com homens, na sua individualidade e no seu agregado social. O que há a fazer é impor método inflexivelmente rigoroso e seguí-1o com devotamento incançável. Examinaremos os delinquentes pelos seus multífaces aspectos, estabelecendo preclassificaçóes de acôrdo com cada um dos caminhos que poderemos seguir na indagação e, depois, sopesando todo o acêrvo de dados recolhidos, vamos procurar estabelecer o gráu de influência de cada um dos factores que ao fim vamos apurar: o factor mesológico e o factor biológico a que já anteriormente fiz referência. Com êste último cálculo, estaremos aptos a estabelecer a classificação do delinquente e a prever, até onde possível ao falaz juízo humano, qual a possibilidade de reincidência e de emendabilidade. Diagnóstico e prognóstico feitos, ao jurista competirá ditar o tratamento.

Se se procurar representar graficamente esta síntese criminiátrica, creio ser possível objectivá-la segundo o desenho anexo.

Nele vemos, na base, uma série de elementos que representam tôda a gama de exames a praticar criminiatricamente: exame somático, funcional, psíquico, psicológico, social, moral e histórico. Cada um dêsses exames, uma vez praticado cuidadosamente, deverá dar em reșultado uma conclusão final que conduzirá a uma classificação do indivíduo em estudo, segundo o caminho seguido; assim, por exemplo, indivíduo pícnico, hipertireoídeo, cicloide, extrovertido, etc. Uma vez chegada a têrmo esta indagação prévia, e em que cada um dos seus elementos tem um valor que não deve ser desprezado, levando em conta duma forma assaz minudénte o elemento histórico, será possível, então, avaliar a existência dos dois elementos primordiais genéticos da acção delituosa, determinando-lhes o gráu de influência, ou, por outro lado, a actuação isolada dum dêsses elementos. E' o primeiro tabulamento da nossa síntese e em que se apôia tudo o mais. Desta indagação resultará a inclusão do indivíduo sindicado num dos grupos da classificação etiológica. Dentro dessa classificação, os dois grupos extremos, biocriminoso e mesocriminoso, verdadeiramente, não são grupos de criminosos, ainda que possam agir de forma a ferir a sociedade: falta-1hes o elemento subjectivo, sem o qual, em rigor, não poderemos falar em crime. Os demais grupos, êsses sim, são classes de verdadeiros criminosos, dentro da conceituação hodierna de acções antissociais. E' bem de ponderar, contudo, que, em face da nossa actual organização jurídico-penal, ainda esta destrinça não possa ser estabelecida de maneira assaz nítida. Daí, figurar numa classificação de criminosos cada um dêsses tipos extre- 
mos, cujo desalojamento dos grupos delinquentes depende da evolução dos conceitos penais ou de defesa social. Classificado o criminoso, mister se faz, dessa tipificação, retirar a previsão possível para a futura readaptação social. Sílvio Marone, recentemente, em trabalho laureado (Prêmio Franco da Rocha), conseguiu de forma assaz escorreita estabelecer, em relação aos grupós verdadeiraménte de criminosos da classificação etiológica, as correspondentes possi-. bilidades de reincidência: ao mesocriminoso preponderante, corres-

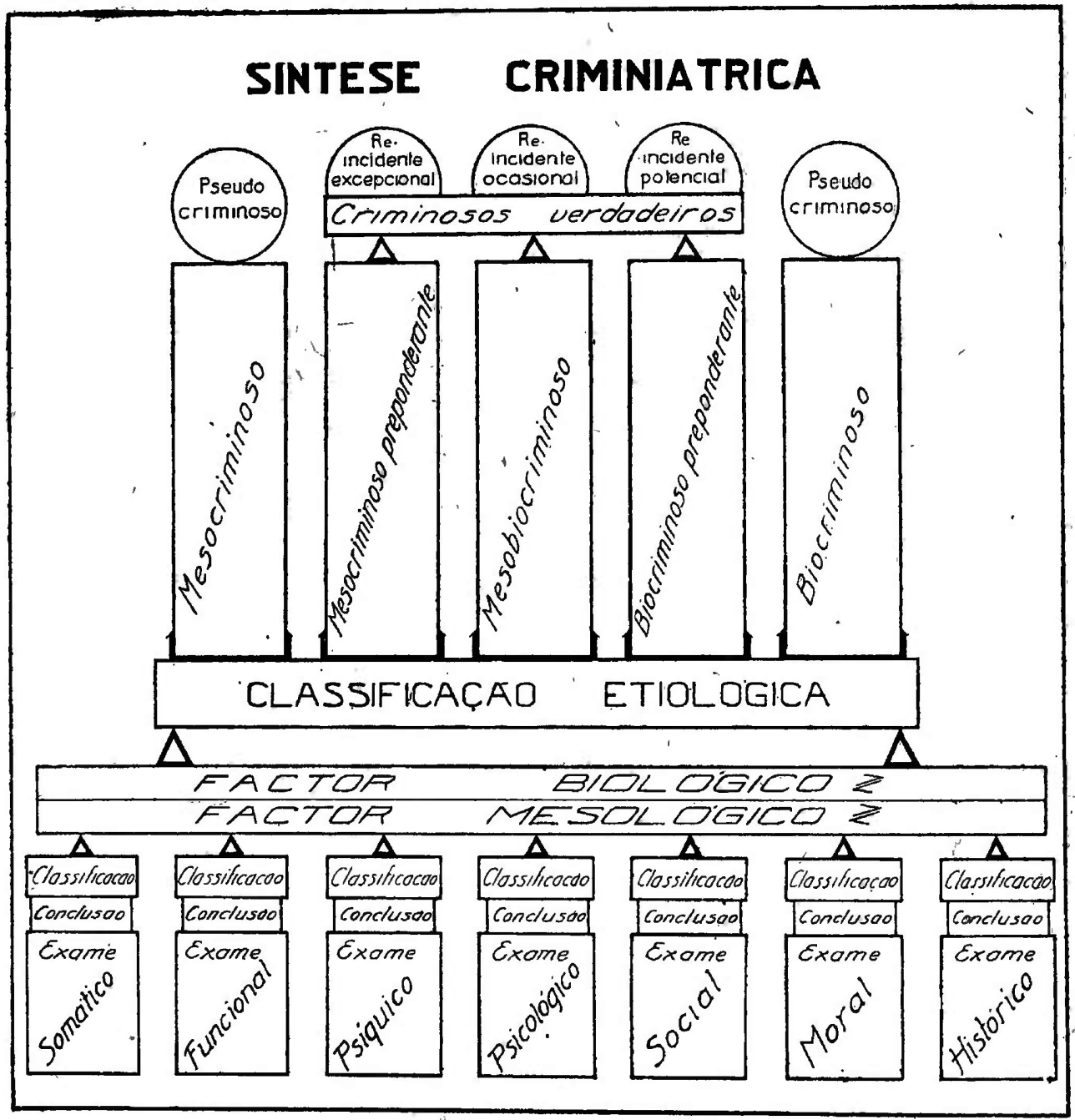

ponderia o reincidente excepcional; ao mesobiocriminoso, corresponderia $\circ$ reincidente ocasional e com o biocriminoso preponderante se relaciona o reincidente potencial. E' bastante explícita esta tabela de equivalências para que necessário se torne uma explanação pormenorizada de cada um dos têrmos escolhidos para a sua nomenclatura. A reincidência é um corolário da emendabilidade, a ela estando intimamente ligada: a previsão da reincidência depende do prognóstico da emendabilidade. As mesmas ligações de interrelação estabelečidas porMarone para a reincidência cabem perfeitamente para o cômputo da emendabilidade. 
$\mathrm{Na}$ síntese criminiátrica que vem de ser arquitectada, colher-se-ão elementos que me parecem suficientes para que um tratamento "penal" possa ser estabelecido. Feita a análise de cada um dos componentes da personalidade do criminoso, estabelecida a gênese do acto delituoso e classificado o tipo criminal a que pertence o indivíduo sindicado, prevista ainda a eventualidade reincidente, está a criminiatria apta a fornecer aos responsáveis pela terapêutica social os elementos fundamentais para o rumo a eleger. Êste, já o assinalei, não é da competência do clínico criminal, senão do jurista. Sem embargo, - e a título apenas de contribuiçã̉o para o estudo dêsse problema, o máximo a resolver - e tomando em consideração a nossa actual organização penitenciária e as suas actuais e próximas possibilidades, parece-me que cada um dos grupos indicados na classificação etiológica poderá ter como tratamento indicado o seguinte: para o biocriminoso, a reclusão no manicômio judiciário, sob a custódia e a marcação do juízo clínico, que definirá ou não a possibilidade do retôrno ao convívio social; para o bioçriminoso preponderante, a colonia correccional, com assistência médico-psiquiátrica, por tempo indeterminado, em relação e dependência do parecer clínico; para o mesobiocriminoso, o sistema penal de reformatório, tal como é levado a cabo na nossa modelar Penitenciária do Estado, com o regime progressivo até a liberdade condicional, tudo em relação com uma orientação médico-pedagógica ao lado do critério jurídico; para o mesocriminoso preponderante, a colônia agrícola, com assistência predominantemente pedagógica; enfim, para o mesocriminoșo, apenas uma educação social apurada e em que se façam sentir os preceitos da higiene mental. É êste um esquema de tratamento social em que me parece terem sido devidamente atendidos $\mathrm{e}$ conjugados os rigores indispensáveis da justiça e os requesitos cada vez mais firmes e aprovados da medicina e da pedagogia. Eu me permito formular tal esquema, repito-o, apenas "como singela contribuição, ainda que o creia exactamente àdequado à realidade actual das nossas condições jurídicas e penitenciárias.

São estas as várias considerações que me pareceu azado aquí debater, ao tentar debuxar uma síntese criminiátrica. Seja-me lícito, após a explanação feita, consignar a prolação dum voto solene: de que. seja, duma forma cada vez mais íntima, entremeada a colaboração da medicina na textura jurídica, pela forma ideal que progressivamente se vái firmando, da clínica criminal, da criminiatria, ao serviço da Justiça, irmanadas que estão ambas congenitamente na procura e na exaltação daquilo que é Bom e daquilo que é Justo. 